\title{
Environmental challenges to operationalisation of South African rainfall enhancement
}

\author{
Karen Shippey ${ }^{1 *}$, André Görgens ${ }^{1}$, Deon Terblanche ${ }^{2}$ and Mike Luger $^{1}$ \\ ${ }^{1}$ Ninham Shand, PO Box 1347, Cape Town 8000, South Africa \\ ${ }^{2}$ South African Weather Service, Private Bag X15, Bethlehem 9700, South Africa
}

\begin{abstract}
Most of the atmospheric moisture in systems moving across South Africa leaves the sub-continent as the weather systems move out over the ocean, only a tenth of it falls on the landmass as rain. An increase in the efficiency of the atmospheric moisture delivery system by means of rainfall enhancement is therefore an attractive concept. Rainfall enhancement functions by either providing additional Cloud Condensation Nuclei or Ice forming Nuclei that will beneficially influence the precipitation formation process, improving the efficiency of moisture to rainfall conversion.

Systematic South African research into rainfall enhancement started in the 1970s. The South African Rainfall Enhancement Programme (SAREP), initiated in the late 1990's, is the most recent in a series of studies and was the first semi-operational rainfall enhancement project to occur in South Africa as a response to drought conditions. In a recent study (DWAF, 2004 in prep) to finalise SAREP and provide guidance on operationalising rainfall enhancement, it was recommended that environmental impact assessment must be undertaken before this technology is implemented further.

Rainfall enhancement falls specifically within the jurisdiction of the National Water Act (NWA) and the National Environmental Management Act (NEMA). A licence to undertake rainfall enhancement activities is required from the Minister of Water Affairs and Forestry after an appropriate environmental impact assessment has been undertaken to inform his decision. This paper proposes an approach to fulfil the legal requirements for operationalising future rainfall enhancement.

The interaction between the science of rainfall enhancement and the ability of scientific disciplines to determine relevant environmental impacts, to appropriately inform the decision-making process, is specifically highlighted. The data requirements identified by scientists during the study varies in duration and resource needs and does not differentiate between ongoing scientific research and the requisite information required for informed decision making. This paper contemplates an approach which provides for holistic and co-ordinated investigation of South African rainfall enhancement into the future.
\end{abstract}

\section{Background}

South Africa is an arid country, with an average annual rainfall of about $480 \mathrm{~mm}$. The low rainfall exacerbated by climatic variation (both natural and human induced) make the country vulnerable to water shortages and threaten food production. These concerns inspired South African scientists to look to the clouds for additional water supply. Research has shown that an average of $10 \%$ of the moisture in atmospheric systems moving across South Africa falls as rain. Most of the atmospheric moisture leaves the sub-continent as the weather systems move out over the ocean.

The terms rainfall enhancement, weather modification and cloud seeding all refer to the artificial introduction of additional particles into clouds around which raindrops can form. In nature, the concentration, size distribution and type of cloud condensation nuclei or ice nuclei are not always suitable for optimum rainfall efficiency. The principle of rainfall enhancement is to release artificial nuclei into the cloud at the right time and location, such that the formation of cloud droplets and ice particles is triggered in a more optimal manner. In so doing, the clouds ability to produce rainfall is enhanced. This technology allows for rainstorms to increase in duration and area rather than intensity. Rainfall enhancement can only stimulate raindrop formation where clouds

This paper was originally presented at the 2004 Water Institute of South Africa (WISA) Biennial Conference, Cape Town, South Africa, 2-6 May 2004.

* To whom all correspondence should be addressed.

용+2721 481-2400; fax: +2721 424-5588;

e-mail: karen.shippey@shands.co.za already exist and meet particular physical criteria; it cannot "create" rain.

Systematic international research of rainfall enhancement dates back to the 1940s and South African research started in the 1970s. The South African Rainfall Enhancement Programme (SAREP), initiated in 1997, was the most recent in a series of studies in rainfall enhancement to occur in South Africa as a response to drought conditions. The "target area" for the SAREP operations was a 100 km x $100 \mathrm{~km}$ block between Polokwane and Tzaneen in the Limpopo Province. Cloud climatology studies for the SAREP project show that a $7-10 \%$ increase in rainfall can be achieved in the target area. The results of much of this work provide sound evidence that the application of rainfall enhancement techniques can result in statistically significant increases in rainfall. The diagram below (Fig. 1) presents a comparison of the average rain mass of seeded and unseeded clouds as measured by radar during SAREP. The average seeded storm produced about 8000 kton more rain than the average un-seeded storm.

\section{Legislation}

Rainfall enhancement is listed in Section 37(1) of the National Water Act (NWA) as a controlled activity requiring authorisation. In the explanatory note to Section 37, the NWA describes controlled activities as requiring specific permission as they may have "a detrimental effect on water resources". In this case, it is likely to increase water resources but the uncertainties center on the potential impact the activity may have on the receiving environment. The NWA says that the Minister of Water Affairs and Forestry must 
Figure 1

Comparison of the average rain mass of seeded and unseeded clouds as measured by radar during SAREP

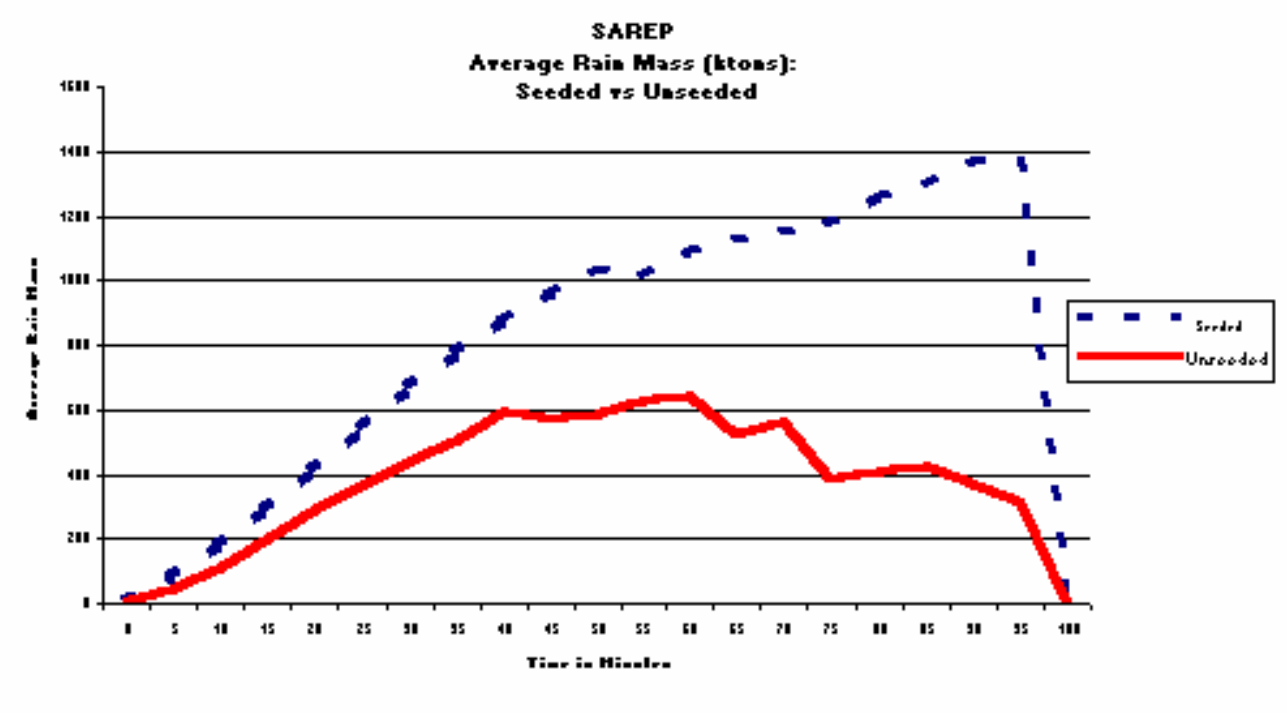

make a decision after a suitable environmental assessment has been undertaken.

The National Environmental Management Act (NEMA) has jurisdiction over environmental assessment and therefore governs the requirements of the studies which need to be undertaken before an authorisation for rainfall enhancement could be considered. NEMA currently provides for a two-prong test as to whether an activity qualifies for an Environmental Impact Assessment (EIA). Section 24 stipulates that, “...activities that require authorisation or permission by law and which may significantly affect the environment, must be considered, investigated and assessed prior to their implementation and reported to the organ of state charged by law with authorising, permitting, or otherwise allowing the implementation of an activity."

In addition, the Minister of Environmental Affairs and Tourism may identify activities, geographic areas or sensitive environments which would be subject to environmental authorization. Until such time as NEMA regulations are promulgated the minimum criteria in Section 24 (7) of the Act provides the only guidance for fulfilling this obligation.

The EIA that is required must fulfil the following minimum criteria:

- Investigation of the affected environment and any alternatives

- Investigation of potential impacts, including cumulative impacts

- Investigation of mitigation measures; and monitoring of mitigation once implemented

- Public information and participation, independent review and conflict resolution

- Reporting of knowledge gaps, underlying assumptions and uncertainties; and

- Coordination and cooperation between organs of state in the consideration of the assessment

\section{Preliminary environmental screening}

As a support study to SAREP, a specialist workshop was held with scientists representing the fields of botany, pedology, zoology, aquatic ecology, atmospheric science and social geography. The purpose of this workshop was to identify potential impacts of rainfall enhancement in order to guide the necessary environmental impact assessment.
The workshop participants used their existing expert knowledge of the target area environment and rainfall enhancement to identify the full suite of potential impacts. Potential environmental impacts were not only given a significance rating, but were also rated in terms of the confidence with which the assessment was made i.e. if there was a large degree of uncertainty regarding the significance of a particular impact and more research is required, it was given a confidence rating of "low".

\section{Physical impacts}

The specialists participating in the Impact Identification Workshop recognised that the potential physical impacts of sustained increased rainfall would have a reasonably predictable effect on the hydrological cycle and its interaction with the topography. This was related to anticipated increased runoff, river flow and the effect on river morphology.

Beyond watercourses, the soil's response to increased water availability are well researched by the agric-scientific community and reliable predictions can be made regarding likely impacts on soil fertility, internal drainage, compaction and erodability. It is however challenging to identify the physical impacts specifically caused by rainfall enhancement due to the natural variability and fluctuation within the hydrological cycle.

Monitoring of water quantity, quality, sedimentation and changes in soil fertility would enhance the certainty with which the scientists could establish the impact. The possible changes in the physical environment are critical in determining the response of the biological system.

\section{Biological impacts}

The effect of increased rainfall on complex ecological interactions is one of the most important considerations in assessing the potential impacts of cloud seeding. Increased rainfall as a result of cloud seeding would be a perturbation imposed on an already variable climate (of which rainfall is but one element), making detection of impacts on the biological environment difficult. This difficulty would be accentuated by the natural fluctuations in species populations of flora and fauna as well as suite of interactions amongst species. The long-term trends and the effects of other 
types of human intervention such as pollution, climate change add further complexity.

Specialists at the workshop indicated that it would be important to establish during which months the extra rain would fall and whether the anticipated increase would be within the standard deviation in natural rainfall.

Within the target area, there may be as many as 20 ecosystems, each of which could respond differently to cloud seeding. Before the potential impact of cloud seeding on the biological environment could be more accurately assessed, the various ecosystems would need to be carefully mapped and classified. This would need to include land use mapping, and the identification of rare ecosystems. A biota inventory would need to be undertaken for each ecosystem and biota identified in order to establish its vulnerability to changes in rainfall patterns, seasonality and distribution.

Baseline ecosystem data gathering exercises in the target area are a prerequisite before ecosystem responses to cloud seeding could be more accurately determined. These baseline situation assessments would have to cover several aspects of the environment, particularly those relating to natural vegetation, certain aquatic subsystems and fauna.

\section{Socio-economic impacts}

Positive social attitudes to and public perceptions of rainfall enhancement are as important to the possible future success of research in this field as overcoming technical hurdles. People from all walks of life seem to have opinions about this issue, regardless of how informed they are. The best defence against misconceptions and false expectations regarding cloud seeding is public education. A comprehensive education programme should therefore form part of any future operational cloud seeding initiative.

The impact identification workshop considered the social impacts relating to public perception and the ethics of rainfall enhancement as well as the potential to develop a dependency on the additional rainfall. Further to this, the relationship between rainfall and human health and migration patterns were also considered. The benefits of additional rainfall to rural communities for basic human water requirements and subsistence farming are considered to be significant. Increased water availability significantly decreases the vulnerability of these communities to drought and increases food security.

The potential beneficiary sectors of rainfall enhancement were identified as forestry and agriculture, water resources and electricity generation (providing additional cooling water for electricity plants). There is a significant potential economic impact in these sectors. Cost-benefit analyses have been undertaken since the early 1990s. A study in the Bethlehem-Nelspruit corridor in a wide range of catchments, using the ACRU daily catchment model, calculated increases in mean annual runoff between $14-42 \%$ and increases in timber yield of $16-30 \%$.

Using the same model, the Vaal River Augmentation Study found that the operational seeding of the whole Vaal Dam catchment would lead to a potential increase of the annual yield of the combined Vaal Dam/Grootdraai Dam system of 12-14\%. The Unit Reference Value (URV) of this seeding-related yield augmentation was $24 \mathrm{c} / \mathrm{m}^{3}$, as compared to structural Vaal Augmentation schemes (e.g. Tugela-Vaal, Lesotho Highlands Phase Two, etc.) which had URVs of $69-136 \mathrm{c} / \mathrm{m}^{3}$ (Görgens and Jewitt, 1995).

Using the same modelling approach as earlier, the cost-benefit analysis for the SAREP target area indicated a cost-benefit ratio of 1.7 for an average increase of $4 \%$ in dryland maize yield, $8 \%$ in dryland grazing yield, $7 \%$ in timber yield and $11 \%$ in reservoir yield, were the whole target area to be fully operationally seeded. The average annual cost of seeding the target area was determined as about R5 million (2000 costs) with a calculated average benefit of R8.5 million (2000 costs) per annum. These cost-benefit analyses are based on conservative estimates of rainfall increases and therefore the potential of this technology to exceed these predictions is high.

\section{Summary of potential impacts}

Although not exhaustive, the list of potential impacts derived from the workshop (Table 1) reflects those identified at the Impact Identification Workshop and by the study team. An attempt has been made to rate each impact according to its potential significance, although in many cases further research and monitoring would be required before this can be more accurately determined. The following information was determined for each impact:

\begin{tabular}{|c|c|}
\hline Impact & $\begin{array}{l}\text { Brief Description/ Name of impacted aspect/ } \\
\text { issue }\end{array}$ \\
\hline Status & Is it a positive or negative impact? \\
\hline Significance & $\begin{array}{l}\text { How important do we believe this impact } \\
\text { will be? }\end{array}$ \\
\hline Confidence & $\begin{array}{l}\text { What confidence do we have in the assigned } \\
\text { significance rating? }\end{array}$ \\
\hline
\end{tabular}

\section{Holistic approach}

It needs to be recognised that although the legislation requires an EIA to be undertaken there is long-term research which is required before scientists will be able to predict the likely effects of rainfall enhancement with any certainty. It is possible that impacts may only be discernable if an activity is undertaken and monitored over extended timeframes. A five to twenty year EIA study is not an appropriate use of this tool, not to mention impractical based on the likely costs involved. Research may focus on a broad understanding of the environmental dynamics and the impacts of a project/ activity at various scales and timeframes. EIAs generally provide reasonable baseline data, but cannot replace the cycle of scientific data collection and analysis over extended periods of time. In this case therefore, the EIA informing a decision on further rainfall enhancement will need to have an adaptive but cautious approach. During the impact identification process undertaken for SAREP no potential impacts have been identified which, on an individual basis, suggest that operational cloud seeding should not be undertaken. Due to the issues raised above regarding timeframes of impact it is suggested that two levels of assessment are required. The first level of assessment may need to be at a strategic level, dealing with issues of whether the overall anticipated risk and cost are acceptable. This Strategic Environmental Assessment (SEA) could set the context and guidelines for further work, undertake an updated cost-benefit analysis and set the research requirements to decrease scientific uncertainty. Importantly, the SEA should include interaction with the public ensuring that a key element of the precautionary principle, namely public engagement, is fulfilled.

Subsequently, should the SEA deem that the technology should be allowed, then organisations that would like to utilise the technology in a specific area, should then be required to undertake a project EIA. Project EIAs would allow for the collection and appraisal of the potential impacts for the specific target area/s. (The possible target areas are limited by physical atmospheric conditions. Figure 2 shows the region within which rainfall enhancement is most likely to be contemplated). 


\begin{tabular}{|c|c|c|c|}
\hline \multicolumn{4}{|c|}{$\begin{array}{c}\text { TABLE } 1 \\
\text { Summary of the potential impacts identified }\end{array}$} \\
\hline Impact & Status & Significance & Confidence \\
\hline \multicolumn{4}{|l|}{ Potential physical impacts } \\
\hline Irrigation & + & High & High \\
\hline Dam yields & + & High & High \\
\hline Streamflow ad run-of river yields & + & High & Low \\
\hline Flooding & - & Medium & Low \\
\hline Reduction in Fire Risk & - & Low & High \\
\hline Increased surface runoff & Uncertain & High & High \\
\hline Soil erosion & Uncertain & Medium & Low \\
\hline Pollution due to seeding agent & - & Low & High \\
\hline Soil fertility & - & High & Low \\
\hline Soil physics & Uncertain & High & Low \\
\hline Lightning & Uncertain & Low & Low \\
\hline Hail & Uncertain & High & Low \\
\hline River morphology & Neutral & High & Low \\
\hline Climate change & + & Medium & Low \\
\hline Water cycle & Uncertain & Low & Medium \\
\hline Groundwater recharge & + & Medium & Low \\
\hline Water temperature & - & Low & Medium \\
\hline Water turbidity & - & Low & Medium \\
\hline \multicolumn{4}{|l|}{ Potential biological impacts } \\
\hline Distribution of vegetation and fauna & Uncertain & High & Low \\
\hline Biodiversity & Uncertain & High & Low \\
\hline Timing of biological processes & - & Medium & Low \\
\hline Faunal behaviour & Uncertain & High & Low \\
\hline Pests & - & Medium & Medium \\
\hline Wetlands & Uncertain & High & Low \\
\hline Biological stress & Uncertain & Medium & Low \\
\hline Natural pasture and fodder production & + & Medium & High \\
\hline Dryland crop production & + & High & Medium \\
\hline Livestock production & + & Medium & Low \\
\hline \multicolumn{4}{|l|}{ Potential social impacts } \\
\hline Conflict and inequities & Uncertain & Low & High \\
\hline Leqal liability & - & High & High \\
\hline Dependency on additional rainfall & Uncertain & Low & High \\
\hline Ethics of enhancing rainfall & - & Low & Medium \\
\hline Diseases & Uncertain & Medium & Low \\
\hline Research and technology & - & High & High \\
\hline Capacity and expertise & Uncertain & High & High \\
\hline Demographics & Uncertain & Low & Medium \\
\hline Competition & Uncertain & Low & Medium \\
\hline Strains on system and infrastructure & - & Low & High \\
\hline Economics & + & High & High \\
\hline
\end{tabular}

Shading = impacts considered to be of high significance

Uncertain = impacts could be negative or positive depending on the circumstances and degree of impact.

The EIA should establish the thresholds within which a seeding project should operate. Are there levels of impact beyond which the risk is too high? Although these may be extremely difficult to set, it is important to require scientists and decision-makers to apply their minds to this question. The EIA therefore provides an opportunity to establish baseline data, determine thresholds and fine-tune monitoring protocols. It is however the ongoing research and adaptive management of the activity which plays the most critical role in any project with high uncertainty.

Figure 2 (right)

Map showing likely target area for future operational cloud seeding

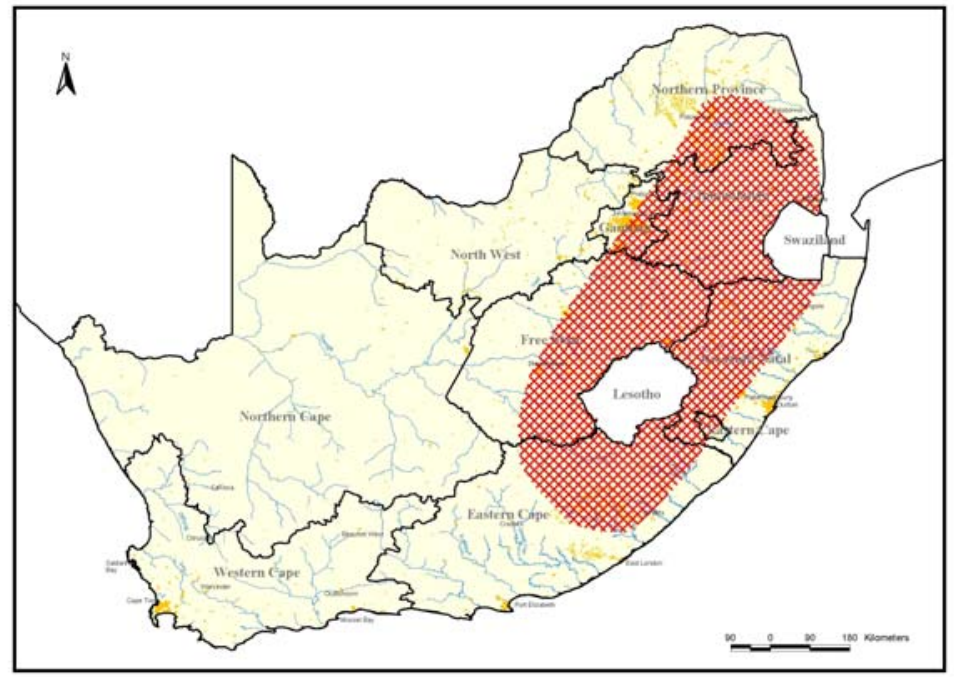




\section{Future challenges}

\section{Legal interpretation}

This methodology requires a flexible approach to EIA and the NEMA requirements since SEA is currently not recognised by legislation as an assessment tool for decision making. The assessment undertaken may meet the minimum requirements in that it may investigate affected environments and alternatives, potential impacts, cumulative impacts, mitigation measures; include public participation, and report knowledge gaps, assumptions and uncertainties. It will however not be able to do these things conclusively. The SEA will not be able to categorically explain the relationship between the activity and the nature and magnitude of the impact. It may not even be able to accurately predict the significance of the potential impact, but it will provide the framework within which all future monitoring and research can be placed.

The Department of Water Affairs and Forestry may need to look further than NEMA Section 24 to guide its investigation of rainfall enhancement. Section 35 of NEMA provides some guidance for complying with the principles of the Act that includes:

- Periodic monitoring and reporting of performance against targets

- Independent verification of reports

- Regular independent monitoring and inspections; and

- Verifiable indicators of compliance with any targets, norms and standards

Using this as a guideline for operations it could be argued that a government controlled pilot scheme be implemented and that this be used as the basis for scientific investigations and a Strategic Environmental Assessment.

\section{Long term monitoring and research}

Preliminary identification of long term monitoring goals was initiated under SAREP but it requires a dedicated study to quantify these goals and develop appropriate protocols for monitoring. Without years of research and baseline data further studies may be ineffective. A harsh reality is that South Africa is sorely lacking in collection of scientific data and long-term ecological research in comparison to first world countries (Walmsley, 1995).

During the SAREP finalisation, a workshop was held with representatives of the sectors that are believed to be the primary beneficiaries of this technology should be it operationalised. It is hoped that future research can be funded by the commercial forestry and agricultural sectors. A co-ordinated effort between private and government researchers is the only realistic way for the true impacts of rainfall enhancement to be determined.

Public Education

During the 1970s and 1980s there are documented instances of extremely negative public reaction to rainfall enhancement experimentation. An organisation called “Red ons Rëen” (Save our Rain) was initiated in direct opposition to the work. Concerns relating to the rain being "stolen" from one area and given to another, the perception that the seeding caused increased lightening and hail and the objection to interference with "God's will” all played a role in the public reaction.
The South African Constitution provides for the public participation in policy making and NEMA enforces this by requiring public participation in EIA and obliging decisions to take note of the issues and concerns of interested and affected parties. An important part therefore of deciding whether or not rainfall enhancement operations should be allowed in South Africa would be to engage with the public on this issue.

The reaction of two decades ago may be repeated unless there is an extensive effort to educate the public regarding the scientific facts relating to rainfall enhancement. It is important to provide accessible information regarding the technology and its potential impacts without creating unrealistic expectations of what can be achieved.

\section{Conclusion}

Rainfall enhancement has been shown to be successful in increasing rainfall, in suitable catchments, at costs that are lower than other conventional water resource augmentation options. To date no potential impacts have been identified which, on an individual basis, suggest that operational cloud seeding should not be undertaken. The law requires an EIA to inform a decision on this matter by the Minister of Water Affairs and Forestry.

An ongoing government rainfall enhancement pilot project with co-ordinated long-term research and a strategic environmental assessment will provide the legal and scientific basis for future implementation of this technology. Further to this, a broad education and public consultation programme is essential to the success of any operationalisation of this technology. This step-wise cautious approach is considered to be the best way to overcoming the environmental challenges to the operationalisation of South African rainfall enhancement.

\section{Acknowledgements}

The authors would like to acknowledge the Department of Water Affairs and Forestry for giving permission for this paper to be based on the draft DWAF report undertaken by Sigma Beta and Ninham Shand entitled "South African Rainfall Enhancement Programme: A Strategic Overview” (DWAF, 2004).

It should be noted that the opinions expressed in this paper are those of the authors and are not necessarily supported by DWAF.

\section{References}

DWAF (2004) South African Rainfall Enhancement Programme: A Strategic Overview Department of Water Affairs and Forestry Draft Document, prepared by Sigma Beta and Ninham Shand.

FOSTER KR, VECCHIA P and REPACHOLI MH (2000) Science and the Precautionary Principle. Science 12 May .

GÖRGENS AHM and JEWITT (1995) Can Vaal Dam Basin Runoff be Augmented by Convective Cloud-seeding? Proceedings of the $7^{\text {th }}$ South African National Hydrology Symposium. Rhodes University, Grahamstown.

SHIPPEY K (2003) EIA, Scientific Endeavor and the Precautionary Principle: Contemplating Rainfall Enhancement in South Africa; International Association for Impact Assessment South African Affiliate 2003 Annual Conference, Wilderness South Africa.

WALMSLEY RD (1995) The Status of Long-Term Ecological Research in South Africa. Foundation for Research Development.

URL: http://www.ilternet.edu/meetings/ilter95/safrica.htm accessed 3 August 2003. 